\title{
Occurrence and Predictors of Persistent Impaired Glucose Tolerance After Acute Ischemic Stroke or Transient Ischemic Attack
}

\author{
Susanne Fonville, $\mathrm{MD},{ }^{*}$ Heleen M. den Hertog, $\mathrm{MD}, \mathrm{PhD},{ }^{*}+$ \\ Adrienne A. M. Zandbergen, MD, PhD, $\ddagger$ Peter J. Koudstaal, MD, PhD, * \\ and Hester F. Lingsma, $\mathrm{PhD} \S$
}

\begin{abstract}
Background: Impaired glucose tolerance is often present in patients with a transient ischemic attack (TIA) or ischemic stroke and doubles the risk of recurrent stroke. This impaired glucose tolerance can be transient, reflecting an acute stress response, or persistent, representing undiagnosed impaired glucose metabolism possibly requiring treatment. We aimed to assess the occurrence of persistent impaired glucose tolerance after a stroke or TIA and to develop a prediction model to identify patients at risk of persistent impaired glucose tolerance. Methods: Patients admitted to the stroke unit or TIA clinic of the Erasmus Medical Center with ischemic stroke or TIA and impaired glucose tolerance (2-hour postload glucose level of 7.8$11.0 \mathrm{mmol} / \mathrm{L}$ ) were consecutively enrolled between July 2009 and June 2012. The oral glucose tolerance test was repeated after 3 months and patients were classified as having transient impaired glucose tolerance or persistent impaired glucose tolerance. We developed a prediction model by means of a multivariable logistic regression model. We calculated the area under the receiver operating characteristic curve (AUC) to quantify the performance of the model and the internal validity by bootstrapping. Results: Of the 101 patients included, 53 (52\%) had persistent impaired glucose tolerance or progression to diabetes. These patients were older and more often had hypertension and used statins. A prediction model including age, current smoking, statin use, triglyceride, hypertension, previous ischemic cardiovascular disease, body mass index, and fasting plasma glucose accurately predicted persistent impaired glucose tolerance (bootstrapped AUC, .777), with statin use, triglyceride, and fasting plasma glucose as the most important predictors. Conclusions: Half of the patients with impaired glucose tolerance after a TIA or ischemic stroke have persistent impaired glucose tolerance. We provide a prediction model to identify patients at risk of persistent impaired glucose tolerance, with statin use, triglyceride, and fasting plasma glucose as the most important predictors, which after external validation might be used to optimize secondary prevention. Key Words: Stroke-TIA-impaired glucose tolerance-prediction model.

(C) 2014 by National Stroke Association
\end{abstract}

From the *Department of Neurology, Erasmus Medical Center, Rotterdam; +Department of Neurology, Medisch Spectrum Twente, Enschede; †Department of Internal Medicine, Ikazia Hospital, Rotterdam; and $\S$ Department of Public Health, Erasmus Medical Center, Rotterdam, The Netherlands.

Received September 15, 2013; revision received January 13, 2014; accepted January 15, 2014.
Address correspondence to Susanne Fonville, MD, Department of Neurology, Erasmus Medical Center, PO Box 2040, 3000 CA Rotterdam, The Netherlands. E-mail: s.fonville@erasmusmc.nl. $1052-3057 / \$$ - see front matter (c) 2014 by National Stroke Association

http://dx.doi.org/10.1016/j.jstrokecerebrovasdis.2014.01.012 


\section{Introduction}

Impaired glucose tolerance is an intermediate metabolic state between normal glucose tolerance and diabetes mellitus, and is present in more than one third of the patients with a transient ischemic attack (TIA) or ischemic stroke. ${ }^{1-10}$ This impaired glucose tolerance can be transient, reflecting an acute stress response, or persistent, representing undiagnosed impaired glucose metabolism. ${ }^{11,12}$ Various studies have found that impaired glucose tolerance is still present after 3 months in $26 \%-71 \%$ of the patients. ${ }^{5-7}$ In patients with a TIA or ischemic stroke, impaired glucose tolerance nearly doubles the risk of recurrent stroke. ${ }^{13}$ It is therefore important to identify patients with persistent impaired glucose tolerance as they might benefit from long-term lifestyle intervention and/or treatment with glucoselowering agents. ${ }^{14-16}$

We aimed to assess the occurrence of persistent impaired glucose tolerance in nondiabetic patients with an ischemic stroke or TIA. We developed a prediction model to identify patients at risk of persistent impaired glucose tolerance, based on clinical predictors available at the time of admission.

\section{Methods}

\section{Study Population}

Patients were derived from the Erasmus Stroke Study, a prospective registry that started in 2005 and collects clinical information and blood samples of all patients with neurovascular diseases admitted to Erasmus University Medical Center Rotterdam, The Netherlands. We prospectively studied all consecutive patients with ischemic stroke or TIA and impaired glucose tolerance (2-hour postload glucose levels between 7.8 and $11.0 \mathrm{mmol} / \mathrm{L}$ ) admitted to the stroke unit or visiting our specialized TIA clinic between July 2009 and June 2012 within 2 weeks after symptom onset. Patients with pre-existent diabetes and patients with 2-hour postload glucose levels of $11.1 \mathrm{mmol} / \mathrm{L}$ or higher (indicating newly diagnosed diabetes mellitus) were excluded. Written informed consent was obtained from all patients signed by the participants or a first-degree relative, as approved by the Institutional Ethics Committee.

\section{Clinical Data}

Demographic data, vascular history and risk factors including statin use, laboratory assessments including lipid profile, and data on event characteristics were collected. Stroke severity was assessed with the National Institutes of Health Stroke Scale score. Stroke subtype was classified with the Trial of ORG 10172 in Acute Stroke Therapy classification. ${ }^{17}$

\section{Glucose Assessments}

In all patients, fasting plasma glucose and glycosylated hemoglobin levels were assessed on the second or third day of admission or when visiting the outpatient clinic, as part of standard clinical care. On the same day, an oral glucose tolerance test (OGTT) was performed according to the World Health Organization protocol. ${ }^{18}$ After overnight fasting, patients drank a solution of $75 \mathrm{~g}$ glucose in $150 \mathrm{~mL}$ water, and 2-hour postload glucose levels were assessed. Impaired glucose tolerance was defined as 2-hour postload glucose levels between 7.8 and $11.0 \mathrm{mmol} / \mathrm{L}$. Patients with fasting plasma glucose levels of $7.0 \mathrm{mmol} / \mathrm{L}$ or higher were diagnosed with diabetes and therefore excluded.

\section{Outcome}

At 3 months, all patients were invited to visit the outpatient clinic and were asked to undergo a second OGTT. The OGTT was repeated and based on the results patients were classified as having transient impaired glucose tolerance (2-hour postload glucose level of $<7.8 \mathrm{mmol} / \mathrm{L}$ ), persistent impaired glucose tolerance (2-hour postload glucose level between 7.8 and $11.0 \mathrm{mmol} / \mathrm{L}$ ), or progression to diabetes (2-hour postload glucose level of $\geq 11.1 \mathrm{mmol} / \mathrm{L})^{1}$

\section{Statistical Analysis}

Statistical analyses were performed with Stata/SE 12.1 for Windows (Statacorp, College Station, TX). Missing variables were imputed with single imputation using the baseline characteristics and the outcome variable. We compared clinical variables between glucose groups, with transient impaired glucose tolerance as a reference. Patients with persistent impaired glucose tolerance or progression to diabetes were grouped together as persistent disturbed glucose tolerance because of the small sample size. The differences between the glucose groups in categorical variables were tested with the $\chi^{2}$ test and continuous variables with the Student $t$ test. Nonnormal distributed variables were compared with the Wilcoxon rank sum test. $P$ values of less than .05 were considered statistically significant.

\section{Model Development}

Possible predictors of persistent impaired glucose tolerance included known risk factors for developing diabetes and other risk factors according to the previous literature: age, sex, ethnicity, current smoking, statin use, lipids (triglycerides, low-density lipoprotein [LDL], and highdensity lipoprotein [HDL]), hypertension, previous ischemic cardiovascular disease, atrial fibrillation (paroxysmal), body mass index (BMI), TIA versus ischemic 
Table 1. Patient characteristics compared between patients with transient and persistent impaired glucose tolerance

\begin{tabular}{|c|c|c|c|}
\hline Patient characteristics & $\begin{array}{l}\text { Transient impaired glucose } \\
\text { tolerance }(\mathrm{n}=48)\end{array}$ & $\begin{array}{l}\text { Persistent impaired glucose } \\
\text { tolerance }(\mathrm{n}=53)\end{array}$ & $P$ value \\
\hline Age $(y)$, mean $(S D)$ & $56(14)$ & $63(14)$ & .017 \\
\hline Male, n (\%) & $31(65)$ & $29(55)$ & .313 \\
\hline Caucasian, n (\%) & $43(90)$ & $45(85)$ & .483 \\
\hline \multicolumn{4}{|l|}{ Vascular risk factors } \\
\hline Current smoking, $\mathrm{n}(\%)$ & $18(38)$ & $11(21)$ & .063 \\
\hline BMI $\left(\mathrm{kg} / \mathrm{m}^{2}\right),{ }^{*}$ mean $(\mathrm{SD})$ & $26.6(4.0)$ & $27.6(5.4)$ & .305 \\
\hline Hypertension, $\dagger \mathrm{n}(\%)$ & $17(35)$ & $35(66)$ & .002 \\
\hline Statin use, n (\%) & $6(13)$ & $21(40)$ & .002 \\
\hline Atrial fibrillation, $\mathrm{n}(\%)$ & $5(10)$ & $6(11)$ & .884 \\
\hline \multicolumn{4}{|l|}{ Vascular medical history } \\
\hline Ischemic cardiovascular disease, $\mathrm{n}(\%)$ & $8(17)$ & $16(30)$ & .111 \\
\hline \multicolumn{4}{|l|}{ Event characteristics } \\
\hline TIA, n $(\%)$ & $17(35)$ & $20(38)$ & .809 \\
\hline Total NIHSS score, median (IQR) $\ddagger$ & $3(1-6)$ & $2(1-4)$ & .232 \\
\hline TOAST classification & & & .885 \\
\hline Large artery disease, $\mathrm{n}(\%)$ & $6(13)$ & $5(10)$ & \\
\hline Cardioembolism, n (\%) & $6(13)$ & $8(15)$ & \\
\hline Small vessel disease, $\mathrm{n}(\%)$ & $17(35)$ & $15(28)$ & \\
\hline Other, $\mathrm{n}(\%)$ & $2(4)$ & $2(4)$ & \\
\hline Undetermined, n (\%) & $17(35)$ & $23(43)$ & \\
\hline \multicolumn{4}{|l|}{ Glucose assessments during admission/visiting TIA clinic } \\
\hline Glucose on admission (mmol/L), mean (SD) & $6.3(1.3)$ & $6.7(1.6)$ & .207 \\
\hline Fasting plasma glucose (mmol/L), mean (SD) & $5.4(.5)$ & $5.5(.6)$ & .135 \\
\hline 2-hour postload glucose (mmol/L), mean (SD) & $8.9(.8)$ & $9.2(.9)$ & .165 \\
\hline Glycosylated hemoglobin $(\mathrm{mmol} / \mathrm{mol}) /(\%)$, mean $(\mathrm{SD})$ & $37(3) / 5.5(.3)$ & $39(4) / 5.7(.4)$ & .027 \\
\hline Days between event and OGTT, median (IQR) & $3(2-5)$ & $2(2-5)$ & .333 \\
\hline \multicolumn{4}{|l|}{ Laboratory assessments during admission/visiting TIA clinic } \\
\hline Total cholesterol (mmol/L), mean (SD) & $5.5(1.1)$ & $5.0(1.2)$ & .058 \\
\hline Triglycerides (mmol/L), mean (SD) & $1.68(.81)$ & $1.43(.58)$ & .151 \\
\hline HDL (mmol/L), mean (SD) & $1.32(.45)$ & $1.37(.43)$ & .611 \\
\hline LDL (mmol/L), mean (SD) & $3.56(1.04)$ & $3.16(1.07)$ & .059 \\
\hline
\end{tabular}

Abbreviations: BMI, body mass index; HDL, high-density lipoprotein; IQR, interquartile range; LDL, low-density lipoprotein; NIHSS, National Institutes of Health Stroke Scale; OGTT, oral glucose tolerance test; SD, standard deviation; TIA, transient ischemic attack; TOAST, Trial of ORG 10172 in Acute Stroke Therapy.

*Missing in 16 patients.

$\dagger$ Defined as the use of antihypertensive drugs before the event.

$\ddagger$ Inpatients with ischemic stroke only.

stroke, large artery atherosclerosis, fasting plasma glucose, 2-hour postload glucose, and glycosylated hemoglobin levels. ${ }^{5-7,19}$ We graphically assessed the shape of relationships between continuous predictors and persistent impaired glucose tolerance with restricted cubic spline functions. When the shape was nonlinear, the variable was transformed according to the observed relation. All potential predictors were tested with univariable logistic regression analysis and those with $P$ value of .20 or less were further analyzed with a multivariable logistic regression model, except for the lipid variables. As the lipid variables are expected to be correlated to statin use, they were first added separately and subsequently simultaneously to the model. This resulted in the basic model to which the glucose levels were added to assess their additional prognostic value.
On the basis of the $-2 \log$ likelihood of the models and the $P$ values of the corresponding $\chi^{2}$, the best prediction model was chosen. The discriminative ability of this model (area under the receiver operating characteristic curve [AUC]) was calculated. The AUC ranges from .50 for noninformative to 1.0 for perfect models. The internal validity of the model was assessed by means of bootstrapping techniques, resulting in an internally validated AUC, which represents the expected performance of the model in future patients.

\section{Results}

\section{Study Population}

Between July 2009 and June 2012, 1176 patients with a TIA or ischemic stroke were admitted to the stroke unit 
or visited the outpatient clinic, and 236 of them had previously been diagnosed with diabetes mellitus. Of the 940 nondiabetic patients, $191(20 \%)$ did not have an initial OGTT, 357 (38\%) had 2-hour postload glucose levels in the normal range, 245 patients $(26 \%)$ had impaired glucose tolerance, and $147(16 \%)$ had 2-hour postload glucose levels in the diabetic range. Of the 245 patients with initially impaired glucose tolerance, 98 patients $(40 \%)$ did not have a repeat OGTT, $31(13 \%)$ had the initial OGTT more than 2 weeks after the event, and $15(6 \%)$ were excluded because they did not have a fasting plasma glucose or it was $7.0 \mathrm{mmol} / \mathrm{L}$ or higher. The remaining 101 patients with initially impaired glucose tolerance and a repeat OGTT were analyzed in this study. The OGTT was not repeated because of the follow-up in another institution (general practitioner, other hospital, or nursing home of residence) (16\% of all patients), test failed or refused by the patient $(5 \%)$, no show $(8 \%)$, event before follow-up (deceased or recurrent stroke) (4\%), or lost-to-follow-up (7\%). Patients who did not undergo a second OGTT compared with those who did were significantly older ( $66 \pm 15$ versus $60 \pm 15$ years; $P=.010)$, and were less often discharged to home ( $37 \%$ versus $79 \%$; $P<.001)$.

\section{Occurrence of Persistent Impaired Glucose Tolerance}

Of the 101 patients, 47 (47\%) had persistent impaired glucose tolerance at 3 months and $6(6 \%)$ had progressed to diabetes. The patient characteristics are shown in Table 1. Patients with persistent disturbed glucose tolerance were older and had more often hypertension and statin use compared with those with transient impaired glucose tolerance. Glycosylated hemoglobin levels were significantly higher in these patients.

\section{Prediction Model}

The shape of relations between persistent impaired glucose tolerance and the continuous variables with the corresponding cutoff points are shown in Figure 1. Age and 2-hour postload glucose levels had a linear relation with persistent impaired glucose tolerance and were analyzed as such. Glycosylated hemoglobin showed a constant risk of less than $39 \mathrm{mmol} / \mathrm{mol}(<5.7 \%)$ and values below that cutoff were truncated. The other nonlinear variables (triglycerides, LDL, HDL, BMI, and fasting plasma glucose) were all truncated in the same way as glycosylated hemoglobin, with the corresponding cutoff points shown in Figure 1.

On the basis of the results of the univariable regression analysis (Table 2), the variables age, current smoking, hypertension, previous cardiovascular disease, BMI, statin use, triglycerides, LDL, fasting plasma glucose, 2-hour postload glucose, and glycosylated hemoglobin levels were selected for the prediction model. All variables were further analyzed with a multivariable logistic regression model, except for the 3 glucose variables. The lipid variables (triglycerides and LDL) were added separately to select the basic model. Adding triglycerides (if $<1.30 \mathrm{mmol} / \mathrm{L}, 1.30 \mathrm{mmol} / \mathrm{L}$ was used; model 2) improved the model significantly $(P=.043)$. However, addition of LDL or both triglycerides and LDL, to the model (models 3-4) did not improve the model significantly (Table 3), so model 2 was chosen as the basic model.

Addition of fasting plasma glucose (if $<5.6 \mathrm{mmol} / \mathrm{L}$, $5.6 \mathrm{mmol} / \mathrm{L}$ was used; model 5) to the basic model significantly improved the model $(P=.024)$. The basic model was not improved after entering 2-hour postload glucose (model $6, P=.390$ ) or glycosylated hemoglobin levels
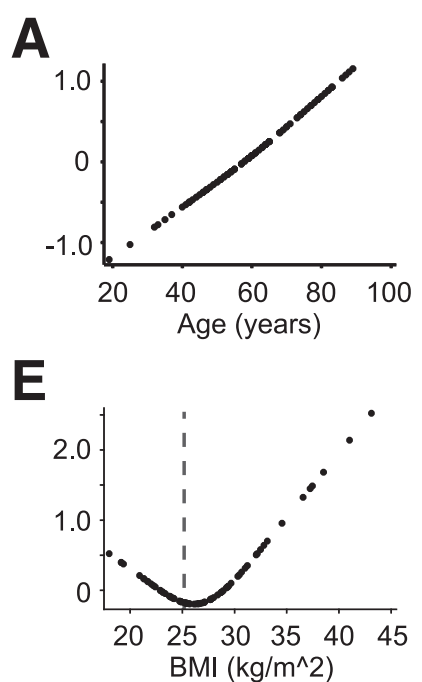
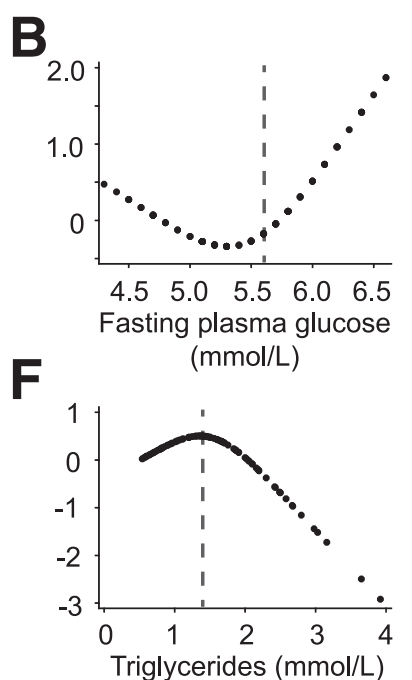

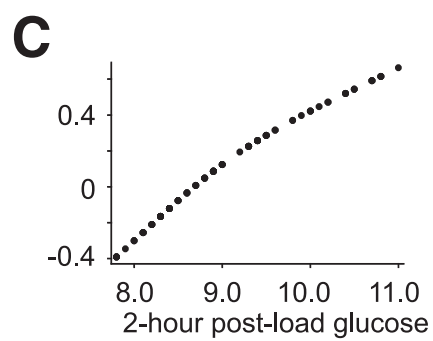

G

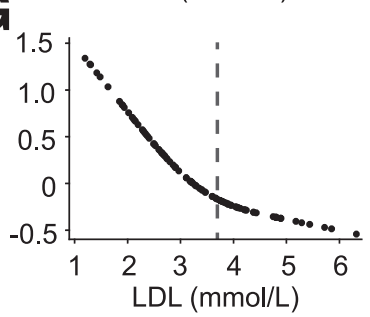

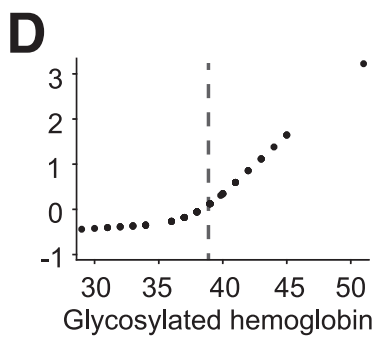

$\mathbf{H}$ $(\mathrm{mmol} / \mathrm{mol})$

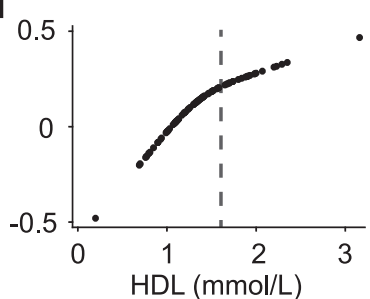

Figure 1. Shape of relations between persistent impaired glucose tolerance and the continuous variables with the corresponding cutoff points (dashed line): (A) age, (B) fasting plasma glucose ( $\geq 5.5 \mathrm{mmol} / \mathrm{L}),(C)$ 2-hour postload glucose, $(D)$ glycosylated hemoglobin $(\geq 39 \mathrm{mmol} / \mathrm{mol}),(E) B M I\left(\geq 25 \mathrm{~kg} / \mathrm{m}^{2}\right),(F) \mathrm{triglyc}-$ erides $(\geq 1.30 \mathrm{mmol} / \mathrm{L}),(\mathrm{G}) \mathrm{LDL}(\leq 3.70 \mathrm{mmol} / \mathrm{L})$, and $(\mathrm{H}) \mathrm{HDL}(\leq 1.60 \mathrm{mmol} / \mathrm{L})$. Linear predictor (log odds) is shown on the $y$-axis. Abbreviations: BMI, body mass index; HDL, high-density lipoprotein; $L D L$, low-density lipoprotein. 
Table 2. Selection of predictors for persistent disturbed glucose tolerance

\begin{tabular}{|c|c|c|}
\hline Possible predictors & OR $(95 \% \mathrm{CI})$ & $P$ value \\
\hline Age (per 10 y) & $1.40(1.05-1.88)$ & .020 \\
\hline Male sex & $.66(.30-1.48)$ & .314 \\
\hline Caucasian & $.65(.20-2.16)$ & .485 \\
\hline Current smoking & $.44(.18-1.06)$ & .066 \\
\hline BMI (per kg/m ${ }^{2}$ ) (if $<25 \mathrm{~kg} / \mathrm{m}^{2}, 25 \mathrm{~kg} / \mathrm{m}^{2}$ was used)* & $1.13(1.00-1.28)$ & .054 \\
\hline Hypertension & $3.55(1.56-8.05)$ & .002 \\
\hline Statin use & $4.59(1.66-12.70)$ & .003 \\
\hline Atrial fibrillation & $1.10(.31-3.86)$ & .884 \\
\hline Previous ischemic cardiovascular disease & $2.16(.83-5.64)$ & .115 \\
\hline Ischemic stroke versus TIA & $.90(.40-2.04)$ & .809 \\
\hline Large artery atherosclerosis versus other causes & $.73(.21-2.56)$ & 622 \\
\hline Triglycerides (per mmol/L) (if $<1.30 \mathrm{mmol} / \mathrm{L}, 1.30 \mathrm{mmol} / \mathrm{L}$ was used) $*$ & $.38(.17-.86)$ & .021 \\
\hline $\mathrm{LDL}($ per $\mathrm{mmol} / \mathrm{L})($ if $\geq 3.70 \mathrm{mmol} / \mathrm{L}, 3.70 \mathrm{mmol} / \mathrm{L}$ was used)* & $.53(.29-.95)$ & .033 \\
\hline $\mathrm{HDL}($ per $\mathrm{mmol} / \mathrm{L})(\text { if } \geq 1.60 \mathrm{mmol} / \mathrm{L}, 1.60 \mathrm{mmol} / \mathrm{L} \text { was used })^{*}$ & $1.89(.50-7.19)$ & .351 \\
\hline Fasting plasma glucose (per mmol/L) (if $<5.6 \mathrm{mmol} / \mathrm{L}, 5.6 \mathrm{mmol} / \mathrm{L}$ was used $)^{*}$ & $6.37(1.16-35.08)$ & .033 \\
\hline 2-hour postload glucose (per mmol/L) & $1.40(.87-2.23)$ & .165 \\
\hline Glycosylated hemoglobin (per mmol/mol) (if $<39 \mathrm{mmol} / \mathrm{L}, 39 \mathrm{mmol} / \mathrm{L}$ was used)* & $1.31(.98-1.76)$ & .064 \\
\hline
\end{tabular}

Abbreviations: BMI, body mass index; CI, confidence interval; HDL, high-density lipoprotein; LDL, low-density lipoprotein; OR, odds ratio; TIA, transient ischemic attack.

Possible predictors with $P$ value of .2 or less were included in the multivariable logistic regression analysis.

*Cutoff point based on Figure 1.

(model 7, $P=.059$ ) (Table 3). Model 5 was therefore chosen as the final prediction model, with a good discriminative disability of .805. The internally validated AUC was .777 , indicating good performance. The strongest predictors in the model were the presence of statin use (adjusted odds ratio [OR] 4.74; 95\% confidence interval [CI], 1.2418.01), triglycerides (adjusted OR, .39; 95\% CI, .16-.96), and fasting plasma glucose (adjusted OR, 8.97; 95\% CI, 1.19-67.70). The risk of persistent impaired glucose toler- ance after a TIA or stroke for individual patients can be calculated with the formula shown below Table 4 .

\section{Discussion}

This study showed that approximately half of the patients with a TIA or ischemic stroke and impaired glucose tolerance had persistent disturbed glucose tolerance after 3 months. We developed a prediction model that

Table 3. Selection of the best basic model and the added value of glucose tests to the model

\begin{tabular}{|c|c|c|c|}
\hline Model & Variables & $\chi^{2}$ & $P$ value \\
\hline 1 & $\begin{array}{l}\text { Age, current smoking, hypertension, previous ischemic } \\
\text { cardiovascular disease, BMI, and statin use }\end{array}$ & 21.40 & Reference \\
\hline \multicolumn{4}{|c|}{ Addition of lipid variables to model } \\
\hline 2 & Model $1+$ triglycerides $(\text { per } \mathrm{mmol} / \mathrm{L})^{*}$ & 25.48 & $.043 \dagger$ \\
\hline 3 & Model $1+$ LDL $($ per mmol/L) $\ddagger$ & 23.84 & $.118 \dagger$ \\
\hline 4 & Model $1+$ triglycerides + LDL & 26.64 & $.073 \dagger$ \\
\hline \multicolumn{4}{|c|}{ Added value of glucose test to model } \\
\hline 5 & Model $2+$ fasting plasma glucose (per mmol/L) $\S$ & 30.56 & $.024 \|$ \\
\hline 6 & Model $2+2$-hour postload glucose (per mmol/L) & 26.22 & $.390 \|$ \\
\hline 7 & Model $2+$ glycosylated hemoglobin (per mmol/mol) $\llbracket$ & 29.06 & $.059 \|$ \\
\hline
\end{tabular}

Abbreviations: BMI, body mass index; LDL, low-density lipoprotein.

*If triglycerides were $<1.30 \mathrm{mmol} / \mathrm{L}, 1.30 \mathrm{mmol} / \mathrm{L}$ was used.

$\dagger$ Compared with model 1.

$\ddagger$ If $\mathrm{LDL}$ was $\geq 1.60 \mathrm{mmol} / \mathrm{L}, 1.60 \mathrm{mmol} / \mathrm{L}$ was used.

$\S$ If fasting plasma glucose was less than $5.6 \mathrm{mmol} / \mathrm{L}, 5.6 \mathrm{mmol} / \mathrm{L}$ was used.

||Compared with model 2.

TIf glycosylated hemoglobin was less than $39 \mathrm{mmol} / \mathrm{mol}, 39 \mathrm{mmol} / \mathrm{mol}$ was used. 
Table 4. Final prediction model to assess the risk of persistent disturbed glucose tolerance

\begin{tabular}{lc}
\hline \multicolumn{1}{c}{ Predictor } & aOR (95\% CI) \\
\hline Age (per 10 y) & $1.18(.79-1.77)$ \\
Current smoking & $.74(.23-2.37)$ \\
Statin use & $4.74(1.24-18.01)$ \\
Triglycerides (per mmol/L) & $.39(.16-.96)$ \\
Hypertension & $2.14(.76-6.01)$ \\
Previous ischemic cardiovascular & $.48(.12-2.03)$ \\
$\quad$ disease & \\
BMI (per kg/m ${ }^{2}$ ) & $1.12(.98-1.28)$ \\
Fasting plasma glucose (per mmol/L) & $8.97(1.19-67.70)$ \\
\hline
\end{tabular}

Abbreviations: BMI, body mass index; CI, confidence interval; aOR, adjusted odds ratio.

Risk of persistent disturbed glucose tolerance: $\exp ($ linear predictor $) /(1+\exp [$ linear predictor $])$. Linear predictor $=-15.607+$ $0.017 \times$ age $-0.308 \times$ current smoking $+1.555 \times$ statin use $0.934 \times$ triglycerides $+0.763 \times$ hypertension $-0.726 \times$ previous ischemic cardiovascular disease $-0.115 \times \mathrm{BMI}+2.194 \times$ fasting plasma glucose. If triglycerides are less than $1.30 \mathrm{mmol} / \mathrm{L}$, use $1.30 \mathrm{mmol} / \mathrm{L}$, if BMI is less than $25 \mathrm{~kg} / \mathrm{m}^{2}$, use $25 \mathrm{~kg} / \mathrm{m}^{2}$, and if fasting plasma glucose is less than $5.6 \mathrm{mmol} / \mathrm{L}$, use $5.6 \mathrm{mmol} / \mathrm{L}$.

$\mathrm{AUC}=.805$, bootstrapped mean $\mathrm{AUC}=.777$.

accurately predicts persistent impaired glucose tolerance (bootstrapped AUC, .777) using age, current smoking, hypertension, previous ischemic cardiovascular disease, BMI, statin use, triglycerides, and fasting plasma glucose, clinical variables readily available on admission. The strongest predictors for persistent impaired glucose metabolism at 3 months were statin use, triglycerides, and fasting plasma glucose.

To our knowledge, only 3 studies repeated the OGTT 3 months after discharge to investigate the persistence of disturbed glucose tolerance after an ischemic stroke. ${ }^{5-7}$ Persistent disturbed glucose tolerance was present in $26 \%-71 \%$ of the patients with $4 \%-42 \%$ progressing to diabetes. $^{5-7}$ Two of these studies found that the 2-hour postload glucose level was a predictor for persistent disturbed glucose tolerance, ${ }^{6,7}$ which is in contrast to our results. This may be because of the small sample size and different statistical analysis methods of these studies.

Impaired fasting glucose and impaired glucose tolerance have different pathophysiological mechanisms: hepatic versus muscle insulin resistance. However, they often coexist indicating more advanced disease and an even higher risk of developing diabetes compared with patients with impaired fasting glucose or impaired glucose tolerance alone. ${ }^{20,21}$ Dyslipidemia is often present in patients with impaired fasting glucose and/or impaired glucose tolerance. This corresponds to the importance of fasting plasma glucose, triglyceride levels, and the presence of statin use in predicting persistent impaired glucose tolerance. ${ }^{19}$

Strengths of our study are the prospective design and the relative large number of cases. Our study has also some limitations. The OGTT was not repeated in $49 \%$ of the patients. As these patients were older, and were less often discharged to home, this affects generalizability of our findings. Because we did not include all patients with a TIA or ischemic stroke admitted to our hospital in our study, we are not able to estimate the prevalence of persistent impaired glucose tolerance in the total stroke population. However, based on data from our center we estimate that approximately $20 \%$ of all patients have pre-existing diabetes. From our study, we have learned that $33 \%$ of the nondiabetic patients have impaired glucose tolerance, and about half had persistent impaired glucose tolerance or progression to diabetes.

Furthermore, this was an observational study and was thus hampered by important missing data. We used imputation to overcome the problem of missing values, which is preferred over complete case analysis. ${ }^{22}$ Of course, our model should be externally validated in an independent comparable population before its use in clinical practice can be recommended.

Our study confirms the hypothesis that disturbed glucose metabolism in the acute phase is not only because of a stress reaction, but might also indicate underlying undiagnosed disturbed glucose metabolism. As impaired glucose tolerance is often present after a TIA or stroke, predicting the persistence of impaired glucose tolerance is very important. These patients do not only have an increased risk of developing diabetes but also an increased risk of recurrent events. Intensive lifestyle intervention and/or antidiabetic drug therapy can be started directly after the TIA or stroke in the patients with high risk of persistent impaired glucose tolerance in the context of secondary stroke prevention. The treatment of impaired glucose tolerance after a TIA or stroke is still subject of several trials. The Metformin and sitAgliptin in patients with impAired glucose tolerance and a recent TIA or minor ischemic Stroke (MAAS) trial (http:// www.trialregister.nl/trialreg/admin/rctview.asp?TC=3196) is a phase II trial currently investigating the feasibility and safety of both metformin and sitagliptin in patients with impaired glucose tolerance after a TIA or ischemic stroke. The Insulin Resistance Intervention after Stroke (IRIS) trial (http://clinicaltrials.gov/ct2/show / NCT00091949) is a phase III trial investigating the effect of treatment with thiazolidinedione drugs on the occurrence of recurrent stroke in patients with a recent TIA or ischemic stroke and insulin resistance.

\section{Conclusions}

To sum up, half of the patients with impaired glucose tolerance after a TIA or ischemic stroke have persistent impaired glucose tolerance. We provide a prediction model to identify patients at risk of persistent impaired glucose tolerance, with statin use, triglyceride, and fasting plasma glucose as the most important predictors, 
which after external validation might be used to optimize secondary prevention.

\section{References}

1. Diagnosis and classification of diabetes mellitus. Diabetes Care 2013;36(Suppl 1):S67-S74.

2. Gray CS, Scott JF, French JM, et al. Prevalence and prediction of unrecognised diabetes mellitus and impaired glucose tolerance following acute stroke. Age Ageing 2004;33:71-77.

3. Kernan WN, Viscoli CM, Inzucchi SE, et al. Prevalence of abnormal glucose tolerance following a transient ischemic attack or ischemic stroke. Arch Intern Med 2005; 165:227-233.

4. Matz K, Keresztes K, Tatschl C, et al. Disorders of glucose metabolism in acute stroke patients: an underrecognized problem. Diabetes care 2006;29:792-797.

5. Vancheri F, Curcio M, Burgio A, et al. Impaired glucose metabolism in patients with acute stroke and no previous diagnosis of diabetes mellitus. QJM 2005;98:871-878.

6. Jia Q, Zheng H, Liu L, et al. Persistence and predictors of abnormal glucose metabolisms in patients after acute stroke. Neurol Res 2010;32:359-365.

7. Dave JA, Engel ME, Freercks R, et al. Abnormal glucose metabolism in non-diabetic patients presenting with an acute stroke: prospective study and systematic review. QJM 2010;103:495-503.

8. Urabe T, Watada H, Okuma Y, et al. Prevalence of abnormal glucose metabolism and insulin resistance among subtypes of ischemic stroke in Japanese patients. Stroke 2009;40:1289-1295.

9. Jia Q, Zheng H, Zhao X, et al. Abnormal glucose regulation in patients with acute stroke across China: prevalence and baseline patient characteristics. Stroke 2012; 43:650-657.

10. Fonville S, Zandbergen AA, Vermeer SE, et al. Prevalence of prediabetes and newly diagnosed diabetes in patients with a transient ischemic attack or stroke. Cerebrovasc Dis (Basel, Switzerland) 2013;36:283-289.

11. Kruyt ND, Biessels GJ, Devries JH, et al. Hyperglycemia in acute ischemic stroke: pathophysiology and clinical management. Nat Rev Neurol 2010;6:145-155.

12. Dungan KM, Braithwaite SS, Preiser JC. Stress hyperglycaemia. Lancet 2009;373:1798-1807.

13. Vermeer SE, Sandee W, Algra A, et al. Impaired glucose tolerance increases stroke risk in nondiabetic patients with transient ischemic attack or minor ischemic stroke. Stroke 2006;37:1413-1417.

14. Knowler WC, Barrett-Connor E, Fowler SE, et al. Reduction in the incidence of type 2 diabetes with lifestyle intervention or metformin. N Engl J Med 2002;346:393-403.

15. Gillies CL, Abrams KR, Lambert PC, et al. Pharmacological and lifestyle interventions to prevent or delay type 2 diabetes in people with impaired glucose tolerance: systematic review and meta-analysis. BMJ 2007;334:299.

16. Lee M, Saver JL, Hong KS, et al. Effect of pre-diabetes on future risk of stroke: meta-analysis. BMJ 2012;344:e3564.

17. Adams HP Jr, Bendixen BH, Kappelle LJ, et al. Classification of subtype of acute ischemic stroke. Definitions for use in a multicenter clinical trial. TOAST. Trial of Org 10172 in Acute Stroke Treatment. Stroke 1993;24:35-41.

18. WHO. Definition, diagnosis and classification of diabetes mellitus and its complications: report of a WHO consultation. Geneva: World Health Organization 1999.

19. Standards of medical care in diabetes-2013. Diabetes Care 2013;36(Suppl 1):S11-S66.

20. Abdul-Ghani MA, Tripathy D, DeFronzo RA. Contributions of beta-cell dysfunction and insulin resistance to the pathogenesis of impaired glucose tolerance and impaired fasting glucose. Diabetes Care 2006;29:1130-1139.

21. Nathan DM, Davidson MB, DeFronzo RA, et al. Impaired fasting glucose and impaired glucose tolerance: implications for care. Diabetes Care 2007;30:753-759.

22. Donders AR, van der Heijden GJ, Stijnen T, et al. Review: a gentle introduction to imputation of missing values. J Clin Epidemiol 2006;59:1087-1091. 